\title{
OEnsino Médio agora é para a vida: Entre o pretendido, o dito e o feito
}

\author{
Acacia Zeneida Kuenzer*
}

\begin{abstract}
RESUMO: O texto propõe-se a desvendar o caráter ideológico do discurso oficial que afirma que o novo Ensino Médio agora é para a vida, em substituição ao modelo que, ao integrar educação geral e profissional em uma mesma rede, era para o trabalho, entendido como "não vida". A autora mostra que, contrariamente ao discurso, a nova proposta atende aos interesses dos incluídos, na perspectiva das demandas da acumulação flexível, apresentando o interesse de uma classe como interesse universal. Para fazê-lo, apresenta a nova proposta como "única", e, por ser igual para todos, democrática; ao contrário, ao tratar igualmente os diferentes, ela é discriminatória e excludente. A autora defende uma proposta que permita a todos ter acesso a todas as áreas do conhecimento, mostrando a possibilidade de a escola pública, ao usar diferentes mediações, minimizar os efeitos das desigualdades decorrentes da precarização cultural em face das diferenças de classe.
\end{abstract}

Palavras-chave: Ensino Médio, educação para o trabalho, educação tecnológica, educação profissional

Aprender para a vida. Esta é a filosofia básica da reforma do Ensino Médio que o Ministério da Educação (MEC) vem implementando no País. A reforma começou com a aprovação da Lei de Diretrizes e Bases da Educação Nacional (LDB), em 1996. Um dos pontos principais da reforma é a separação da Educação Profissional do ensino regular. A partir de agora, a formação técnica é um complemento da Educação geral e não

um pedaço dela. Com essa mudança, o ensino profissional pode ser

\footnotetext{
*Professora do Setor de Educação, UFPR. Email: acaciazk@uol.com.br
} 
cursado ao mesmo tempo que o Ensino Médio, mas o aluno tem que fazer os dois cursos para receber o diploma. (Folha de S. Paulo, 19/8/99)

Assim, ninguém discutiria que o legislador deve ocupar-se sobretudo da educação dos jovens. De fato, nas cidades onde não ocorre assim, isso provoca danos aos regimes, uma vez que a educação deve adaptar-se a cada um deles: pois, o caráter particular a cada regime não apenas o preserva, como também o estabelece em sua origem; por exemplo, o caráter democrático engendra a democracia e o oligárquico a oligarquia, e sempre o caráter melhor é causante de um regime melhor. (Aristóteles, Política, VII, 1 e 2, citado por Mello, no parecer do CNE sobre Diretrizes

Curriculares para o Ensino Médio)

A novidade, portanto, é que um sistema que produz e agrava constantemente adversidades, injustiças e desigualdades possa fazer com que tudo isso pareça bom e justo. A novidade é a banalização das condutas injustas que lhe constituem a trama (...). Não há banalização da violência sem ampla participação num trabalho rigoroso envolvendo a mentira, sua construção, sua difusão, sua transmissão e sobretudo sua racionalização.

(Dejours 1999, pp. 139 e 133)

\section{Introdução}

O MEC, em propaganda veiculada pela mídia em agosto e setembro de 1999, citada em epígrafe, vem afirmando que a partir de agora o Ensino Médio é para a vida, em contraposição à proposta anterior, que supostamente, ao preparar para o trabalho, não preparava para a vida. Complementa a afirmação dizendo que o jovem até pode fazer um curso profissional, desde que em outra rede, em outro curso que não o Médio, de forma concomitante ou complementar.

Numerosas análises já foram feitas mostrando que a proposta para o Ensino Médio em vigor, consubstanciada na Resolução 03/98 do CNE, é parte integrante das políticas educacionais propostas pelo governo Fernando Henrique Cardoso, que por sua vez expressam uma concepção de educação orgânica ao modelo econômico em curso, versão nacional do processo globalizado de acumulação flexível.

Como muito propriamente anuncia Mello já na epígrafe do primeiro texto do parecer sobre as Diretrizes Nacionais para o Ensino Médio, citando Aristóteles, a ninguém ocorreria pensar que uma proposta de educação das jovens gerações não expressasse uma proposta de governo, que por sua vez corresponde a uma concepção de sociedade e de ho- 
mem que é fruto da opção política de um grupo que ocupa o poder em decorrência da correlação de forças historicamente dada.

Essa concepção particular, apresentada como consensual, só pode se sustentar pela difusão de um discurso pronto, assimilado individualmente, mas fabricado externamente ao sujeito, isto é, que Ihe seja imposto. Para que todos assumam o mesmo discurso, é preciso que ele passe a ser dominante, para o que é decisiva a estratégia comunicacional, no dizer de Dejours, distorcida, na medida em que consiste em uma racionalização construída e difundida para atender a interesses determinados. A teorização sobre tal fenômeno não é novidade, uma vez que se inscreve no campo da construção da hegemonia, onde as ideologias desempenham papel central (Marx e Engels, s./d.; Gramsci 1978).

Compreender a Reforma do Ensino Médio, portanto, exige que se elucidem as concepções, preenchendo o discurso lacunar, para que as intencionalidades decorrentes de interesses e visões particulares de mundo, próprias das diferentes posições de classe, venham à tona, e assim se possa exercer o direito de escolha por possíveis históricos que são necessariamente contraditórios, dentro dos limites da democracia possível.

Desnudar o caráter parcial e interessado das ideologias, como postulam os clássicos marxistas, ou proceder sistemática e rigorosamente à desconstrução da distorção comunicacional nas empresas e organizações sociais, destruindo a mentira por meio do discurso científico, como quer Dejours (1999, p. 135), é uma das tarefas necessárias ao se pretender compreender os acertos e desacertos da proposta oficial de currículo para o Ensino Médio, desde que se tenha claro para quem são esses acertos.

Neste trabalho, o propósito é elucidar os desacertos, tendo em vista a construção de um referencial, não apenas crítico, mas propositivo, que subsidie o esforço coletivo para combater os efeitos crescentemente excludentes das opções nos campos da política econômica e social, particularmente no que diz respeito à educação.

Com esse objetivo, mas sem a pretensão de esgotar a análise, o texto discutirá algumas racionalizações construídas pelo discurso governamental com base no ideário neoliberal, apontando suas contradições, no sentido de sua desconstrução, procurando elucidar os conceitos, as propostas e as intencionalidades. E, ao mesmo tempo, buscará trazer ao debate algumas proposições, tendo em vista a construção de um projeto político-pedagógico orgânico às necessidades dos excluídos dos benefícios da globalização. 


\section{Unitariedade x dualidade: O direito à diferença sem desigualdade}

As mudanças ocorridas no mundo do trabalho têm trazido à agenda político-pedagógica novas demandas de formação humana, e, em que pese as pesquisas estarem reiteradamente apontando a tendência à polarização das qualificações, esta é uma questão fundamental para o enfrentamento da exclusão. Esse debate aponta algumas dimensões que precisam ser consideradas, sobre as quais tem havido consenso nos eventos que têm discutido as políticas públicas de educação contemporaneamente:

- a necessidade de expansão da oferta de Ensino Médio até que se atinja a sua universalização, uma vez que não é possível a participação social, política e produtiva sem pelo menos 11 anos de escolaridade; em decorrência, o Ensino Médio perde o seu caráter de intermediação entre os níveis fundamental e superior, para constituir-se na última etapa da educação básica; essa constatação encaminha, de fato, para a construção de um sistema unitário no que diz respeito à educação básica, como resposta às demandas da acumulação flexível;

- ao mesmo tempo, já não se entende possível a formação profissional sem uma sólida base de educação geral, exigindo-se a superação da ruptura historicamente determinada entre uma escola que ensine a pensar, por intermédio do domínio teórico-metodológico do conhecimento socialmente produzido e acumulado, e uma escola que ensine a fazer, pela memorização de procedimentos e do desenvolvimento de habilidades psicofísicas; em decorrência, a acumulação flexível demanda a superação de um paradigma dual, que polariza técnicas e humanidades, apontando a educação tecnológica como uma síntese possível entre ciência e trabalho.

A pergunta que se impõe é se a proposta curricular para o Ensino Médio apresentada pelo governo responde a essas novas determinações, e para quem; os argumentos apresentados a seguir apontam para uma resposta negativa à primeira parte da indagação, e indicam a organicidade da nova proposta aos interesses dos incluídos.

\section{A construção da unitariedade não é um problema pedagógico}

As mudanças ocorridas no mundo do trabalho apontam para uma nova forma de relação entre ciência e trabalho, na qual as formas de fazer - determinadas com base em processos técnicos simplificados, restritos geralmente a uma área do conhecimento, transparentes e, portanto, facilmente identificáveis e estáveis - passam a ser substituídas por ações que 
articulem conhecimento científico, capacidades cognitivas superiores e capacidade de intervenção crítica e criativa perante situações não previstas, que exigem soluções rápidas, originais e teoricamente fundamentadas, para responder ao caráter dinâmico, complexo, interdisciplinar e opaco que caracteriza a tecnologia na contemporaneidade.

Essa nova realidade exige novas formas de mediação entre o homem e o conhecimento, que já não se esgotam no trabalho ou no desenvolvimento da memorização de conteúdos ou formas de fazer e de condutas e códigos éticos rigidamente definidos pela tradição taylorista/ fordista, compreendida não só como forma de organização do trabalho, mas da produção e da vida social, na qualidade de paradigma cultural dominante nas sociedades industriais modernas.

Tais novas formas de mediação passam necessariamente pela escolarização, inicial e continuada, com a construção de um novo projeto educativo que articule as finalidades de educação para a cidadania e para o trabalho com base em uma concepção de formação humana que, de fato, tome por princípio a construção da autonomia intelectual e ética, por meio do acesso ao conhecimento científico, tecnológico e sócio-histórico e ao método que permita o desenvolvimento das capacidades necessárias à aquisição e à produção do conhecimento de forma continuada.

Compreendida dessa forma, a formação humana para a vida social e produtiva não mais repousa sobre a aquisição de modos de pensar e fazer bem definidos, individuais e diferenciados de acordo com o lugar a ser ocupado na hierarquia do trabalhador coletivo, deixando de ser concebida, como o faz o taylorismo/fordismo, como conjunto de atributos individuais, psicofísicos, comportamentais e teóricos, prévia e socialmente definidos.

Ao contrário, passa a ser concebida como resultante da articulação de diferentes elementos, pela mediação das relações que ocorrem no trabalho e na vida coletivos, resultando de vários determinantes subjetivos e objetivos, como a primeira socialização, a natureza das relações sociais vividas e suas articulações, a escolaridade, o acesso a informações, o domínio do método científico, a origem de classe, a duração e a profundidade das experiências laborais e sociais, o acesso a espaços, saberes, manifestações científicas e culturais, e assim por diante.

Em decorrência, a qualificação profissional passa a repousar sobre conhecimentos e habilidades cognitivas e comportamentais que permitam ao cidadão/produtor chegar ao domínio intelectual da técnica e 
das formas de organização social, de modo que seja capaz de criar soluções originais para problemas novos, que exigem criatividade, pelo domínio do conhecimento.

Para tanto, é preciso outro tipo de pedagogia, determinada pelas transformações ocorridas no mundo do trabalho nessa etapa de desenvolvimento das forças produtivas, para atender às demandas da revolução na base técnica de produção, com seus profundos impactos sobre a vida social. O objetivo a ser atingido é a capacidade para lidar com a incerteza, substituindo a rigidez por flexibilidade e rapidez, a fim de atender a demandas dinâmicas, que se diversificam em qualidade e quantidade, não para ajustar-se, mas para participar como sujeito na construção de uma sociedade em que o resultado da produção material e cultural esteja disponível para todos, assegurando qualidade de vida e preservando a natureza.

A elaboração de uma nova proposta pedagógica que conduza a essa formação de novo tipo não é um problema pedagógico, mas um problema político. Não basta, pois, fazer a crítica à orientação taylorista/ fordista que fundamentava os currículos dos cursos técnicos que tinham por objetivo formar para ocupações de nível intermediário, porém bem definidas por um mercado de trabalho típico de uma economia pouco dinâmica, cuja tecnologia era relativamente estável. Ou mesmo aos cursos profissionais do Sistema $\mathrm{S}$, que tinham essa mesma natureza.

Com base nessa crítica, não basta afirmar que a nova educação média deverá ser tecnológica - e, portanto, organizada para promover o acesso articulado aos conhecimentos científicos, tecnológicos e sócio-históricos - e, ao mesmo tempo, extinguir os cursos profissionalizantes, estabelecendo por decreto que a dualidade estrutural foi superada por meio da constituição de uma única rede, o que justificou, inclusive, a não discussão de formas de equivalência entre Ensino Médio e profissional.

Essa solução fácil, porque formal e restrita ao âmbito do pedagógico, não é suficiente para transformar a realidade de uma sociedade dividida pelas novas/velhas relações que o neoliberalismo estabelece entre capital e trabalho, na qual o crescimento da exclusão e a diminuição dos recursos públicos, que permitiriam a formulação de políticas e projetos necessários à garantia dos direitos mínimos de cidadania, não são distorções, mas a própria natureza do modelo. Pelo contrário, é uma solução ideológica porque desconsidera a realidade do modelo econômico brasileiro, com sua carga de desigualdades decorrentes das diferenças de classe e de especificidades resultantes de um modelo de desen- 
volvimento desequilibrado, que reproduz internamente as mesmas desigualdades e os mesmos desequilíbrios que ocorrem entre os países, no âmbito da internacionalização do capital.

A dualidade estrutural que determinou duas redes diferenciadas ao longo da história da educação brasileira tem suas raízes na forma de organização da sociedade, que expressa as relações entre capital e trabalho; pretender resolvê-la na escola, por meio de uma nova concepção, é ingenuidade ou má-fé.

Em decorrência, pode-se afirmar que a materialidade da escola média brasileira, produto histórico de um determinado modelo de organização social, econômica e política, não oferece condições para a unitariedade, a não ser em outro modelo de sociedade.

Resta saber, portanto, a que interesses serve a disseminação da idéia de que o novo Ensino Médio atende aos princípios da escola única. Uma forma de fazê-lo é buscar compreender a quem se destina e como se insere esse nível de ensino no conjunto da reforma que vem sendo levada a efeito desde a aprovação autoritária da LDB. Ao mesmo tempo, essa análise permitirá demonstrar que o Ensino Médio continua, sob a falsa idéia da unitariedade, perversamente mais dual.

Dualidade e elitização: A reedição do currículo secundarista como estratégia conservadora

Uma análise superficial das mudanças ocorridas no mundo do trabalho certamente levaria à conclusão de que está em curso um processo de elevação generalizada da educação da população, tendo em vista sua participação mais qualificada na vida geral e produtiva. De fato, essa conclusão seria mais lógica, uma vez que a educação do trabalhador de novo tipo funda-se no desenvolvimento de um conjunto de comportamentos, habilidades e atitudes que só a educação escolar, no mínimo básica, poderá assegurar. No entanto, mesmo considerando até os cursos pós-médios, os resultados têm sido insatisfatórios em relação às novas demandas, pois estas exigem competências em investigação científica, em comunicação e em análise crítica das relações sociais e produtivas, que muitos cursos de graduação não conseguem desenvolver.

No Brasil, em que pese toda a carga de desigualdades e de crise econômica e institucional, este foi por algum tempo o discurso que uni- 
ficou trabalhadores, empresários e Estado, com a mediação de seus intelectuais, passando a integrar as finalidades da educação na LDB, em que se faz particular alusão à educação básica como condição de continuidade de formação, de compreensão dos fundamentos científicotecnológicos do trabalho e de formação ética e crítica, tendo em vista a participação cidadã nas relações sociais e produtivas.

Contudo, um debruçar mais cuidadoso sobre os resultados do modelo de desenvolvimento em curso aponta para outro cenário, que compromete radicalmente a possibilidade histórica de concretização desse discurso: o acirramento da dependência externa, o predomínio de investimentos de caráter especulativo, a corrosão dos fundos públicos pela própria natureza da globalização, com os agravantes da sonegação e da renúncia fiscal, para não falar em mau uso e corrupção, tudo culminando com o fechamento de postos de trabalho e com o aumento da exclusão.

Não é por acaso que as pesquisas realizadas no Brasil apontam para a tendência à polarização das competências, através de um sistema educacional que articule formação e demanda, de tal modo que à grande maioria da população assegure-se, no máximo, acesso à educação básica, fundamental e média, e mesmo assim a longo prazo, para que possa exercer alguma tarefa precarizada na informalidade ou no mercado formal. A oferta de educação científico-tecnológica mais avançada fica restrita a um pequeno número de trabalhadores, e, assim mesmo, de forma hierarquizada, com níveis crescentes de complexidade que vão do pósmédio à pós-graduação. Mesmo entre os trabalhadores incluídos vêm se construindo diferenciações, criando-se novas categorias de profissionais qualificados em processo permanente de competição, definindo-se a nova concepção de empregabilidade como resultante do esforço individual e fundada na "flexibilidade", como capacidade para adequar-se a mudanças, mesmo quando significam perda de direitos e de qualidade de vida, como por exemplo ocorre com a intensificação do trabalho.

Embora o discurso oficial reproduza o compromisso com a generalização da educação básica, modelo do mundo desenvolvido, que mesmo não tendo resolvido a questão do emprego já atinge patamares elevados de educação superior para a população, no Brasil ainda lutamos para universalizar o ensino básico para os que estão na faixa de 7 a 14 anos; para os trabalhadores adultos, considerando o número de anos de escolaridade da População Economicamente Ativa (PEA), por volta de quatro anos, a política oficial tem seu limite no supletivo, como expressão do abandono da cena de luta em face da magnitude do esforço que seria ne- 
cessário fazer para vencer uma dívida social de 500 anos. Em decorrência, boa parte do esforço de escolarização dos trabalhadores incluídos tem sido assumido pelas empresas, dada a insuficiência das políticas públicas. O resultado tem sido a manutenção de uma grande massa de excluídos do sistema de educação regular e profissional, que tende a crescer, caso não haja políticas públicas mais incisivas em relação ao acesso e à permanência, particularmente de jovens e adultos.

Em virtude do elevado investimento que seria necessário para universalizar pelo menos o Ensino Médio nos países periféricos, o Banco Mundial tem recomendado que se priorize o Ensino Fundamental, deixando de investir em educação profissional especializada e de elevado custo como estratégia de racionalização financeira com vistas ao atingimento das metas de ajuste fiscal. Tal recomendação vem respaldada em pesquisa encomendada pelo próprio banco, que conclui ser o nível fundamental o de maior retorno econômico e ser irracional o investimento em um tipo de formação profissional cara e prolongada, em face da crescente extinção de postos e da mudança do paradigma técnico para o tecnológico.

Ao mesmo tempo, a pesquisa aponta a irracionalidade do investimento em educação acadêmica e prolongada para aqueles que, segundo os resultados da investigação, são a maioria e não nascem competentes para o exercício de atividades intelectuais: os pobres, os negros, as minorias étnicas e as mulheres. Para estes, mais racional seria oferecer educação fundamental, padrão mínimo exigido para participar da vida social e produtiva nos atuais níveis de desenvolvimento científico e tecnológico, complementada por qualificação profissional de curta duração e baixo custo.

As políticas de educação profissional no Brasil, articuladas às de educação geral a partir de 1996, adotam essa lógica, justificada pela racionalidade econômica que prevê inclusive o repasse progressivo das ações do Estado para a esfera privada. Assim é que a prioridade tem sido a universalização do Ensino Fundamental para a faixa etária correspondente, acompanhada por programas de correção que pretendem regularizar o fluxo idade/série daqui em diante, como forma de não mais se produzir déficit de escolaridade.

A partir desse nível, o Estado se descompromete com a universalização, prevista na Constituição para ser atingida progressivamente, e passa a trabalhar com o conceito de eqüidade, no sentido de dar a cada um segundo sua diferença, para que assim permaneça. Assim concebida, a eqüidade toma a diferença não como desigualdade, mas como atributo natural, próprio do ser humano. Em seus documentos 
para os países pobres, o Banco Mundial adota esse conceito, justificando a inadequação da concepção de universalização, posto que as diferentes competências resultam de atributos "naturais", que não se alteram significativamente pela permanência no sistema educacional. Dessa ótica, a universalização significa desperdício, e, portanto, sofisticação imprópria para países em crise, que devem priorizar investimentos com maior possibilidade de retorno (Banco Mundial 1995).

Assim, para a PEA são oferecidos cursos de qualificação e reconversão profissional, que passam a substituir, na prática, a educação básica, embora não seja esta a compreensão do Ministério do Trabalho e do Emprego. Esses cursos obedecem à regulamentação do Decreto 2208/97, que institui o Sistema Nacional de Educação Profissional em paralelo ao Sistema Nacional de Educação. No âmbito desses dois sistemas, e de forma orgânica, realizam-se as reformas do ensino técnico e médio, com o que foram extintas as escolas técnicas de nível médio. Restabelecem-se as duas trajetórias, sem equivalência, negando-se a construção da integração entre educação geral e educação para o trabalho que vinha historicamente se processando nas instituições responsáveis pela educação profissional, certamente mais orgânica à nova realidade da vida social e produtiva (Kuenzer 1997).

Essa reforma constituiu-se em um ajuste conservador, que retrocede aos anos 40, quando a dualidade estrutural, agora revigorada, estabelecia uma trajetória para os intelectuais e outra para os trabalhadores, entendendo-se que essas funções eram atribuídas com base na origem de classe. Mesmo considerando que a universalização da educação básica vem sendo defendida de forma unânime por distintos atores sociais, que a formação para o trabalho anterior a ela é precoce e precária, e que o Primeiro Mundo já resolveu esse estágio, é preciso levar em conta as peculiaridades do caso brasileiro, onde a inexistência de dotação orçamentária ainda se mantém e apenas $25 \%$ dos jovens em idade de Ensino Médio são atendidos.

Ou seja, a universalização desse nível, se chegar a ser prioritária, será resultado de trabalho de décadas. Do mesmo modo, a necessária superação da dicotomia entre ensino técnico e ensino propedêutico pelo Ensino Médio tecnológico, como propõe a Resolução 03/98 do Conselho Nacional de Educação, exige tamanho investimento que não é preciso muito esforço para concluir que teremos longos anos de Ensino Médio secundarista pela frente. Basta analisar os recursos disponíveis nos orçamentos públicos das unidades federadas e da União, que mal cobrem os custos básicos de um sistema insuficiente e inadequado, para se ter clareza de que a universalização do acesso ao nível médio não está presente no or- 
çamento da União, a não ser na forma de financiamento por intermédio de agentes financeiros internacionais.

Mais recentemente, o Governo Federal está envidando esforços para obter do Legislativo autorização para utilizar parte dos recursos do salárioeducação para financiar esse nível de ensino. O difícil será equacionar, se for autorizada, essa repartição, uma vez que vários estudos já mostram que, mesmo nos municípios que asseguram o bom uso dos recursos, na maioria dos casos eles são insuficientes para cobrir os custos da universalização do Ensino Fundamental com qualidade. E, mesmo que estivessem assegurados recursos específicos, a universalização do Ensino Médio é uma tarefa de longo prazo, em face do baixo percentual de atendimento à demanda por esse nível de ensino.

A democratização do Ensino Médio, no entanto, não se encerra na ampliação de vagas. Ela exige espaços físicos adequados, bibliotecas, laboratórios, equipamentos, e, principalmente, professores concursados e capacitados. Sem essas precondições, discutir um novo modelo, pura e simplesmente, não resolve a questão.

A reforma educacional levada a efeito neste governo só se mostra completa quando se analisa a atual proposta para o Ensino Superior, que até a homologação da LDB articulava formação e profissionalização. A partir dessa lei, os currículos mínimos, certamente rígidos, anacrônicos e cartoriais, foram substituídos por diretrizes curriculares amplas e gerais, que asseguram flexibilidade à instituição e aos alunos para definir propostas que atendam às novas demandas com suas especificidades regionais, locais e individuais. Em resumo, a proposta é que cada curso seja uma trajetória, para atender às demandas de formação flexível.

Assim é que, de modo geral, os documentos preliminares estabelecem competências a serem desenvolvidas, de maneira que não seja oferecida profissionalização altamente especializada, mas as bases sobre as quais as especialidades poderão se estabelecer. A essa formação básica sucedem ênfases, ofertadas pela escola e escolhidas pelo aluno, que por sua vez fará também escolhas entre disciplinas optativas para atender a suas preferências. Ou seja, o currículo com $50 \%$ de disciplinas obrigatórias e suas ênfases reinventa a taylorização, agora pós-moderna, sob a justificativa da flexibilização, que facilmente substituirá a atual formação específica, e já insuficiente, por uma formação inespecífica, aligeirada e de baixo custo, transferindo-se a especialização para a pós-graduação, como sugerem as orientações do MEC no Edital $n^{\circ}$ 4, de 1997. Para a empregabilidade, vale o que diferencia, aquilo que se tem a mais. 
Assim, o cenário da profissionalização no Ensino Superior, para os concluintes do Ensino Médio propedêutico e elitizado, lembra mais um grande shopping onde quem mais tem, inclusive tempo, mais compra, para enfrentar os desafios da competitividade. O espaço para o trabalho disciplinado e metódico que a relação com o conhecimento exige, no processo de construção de significados e de produção científica, fica postergado para outro nível, ainda mais elitizado: 0 da pós-graduação.

Dessa forma, pode-se compreender a política de educação profissional formulada para o Brasil nos próximos anos; sua lógica confirma a afirmação feita no início do texto, de que na "sociedade do conhecimento" ela é para poucos. Compreende-se, também, a sua organicidade com o modelo de acumulação flexível, que exige formação de novo tipo, a integrar ciência, tecnologia e trabalho, para os privilegiados ocupantes dos poucos postos que não correm risco de precarização, que "nasceram competentes para estudar" e que certamente não são os pobres. Realiza-se a recomendação do Banco Mundial de não se investir em formação especializada, custosa e prolongada, para uma população que viverá com poucos direitos, na informalidade, e que, ironicamente, "gozará de autonomia para fazer suas escolhas, ter seu próprio negócio, definir seu ritmo e horário de trabalho e seu tempo livre". Contraditoriamente, os que ocupam os cargos que restam têm seu trabalho cada vez mais intensificado.

Essa política é perversamente orgânica às novas demandas da acumulação flexível, que inclusive determina, quando há adesão dos dirigentes ao bloco hegemônico, o lugar que cada país ocupará na economia globalizada. Nesse sentido, a renúncia à educação científico-tecnológica de alto nível para o maior número possível de trabalhadores corresponde à renúncia à produção científica, o que equivale a dizer, à construção de um projeto soberano de nação, trocado pela eterna dependência científica, econômica e política.

\section{Diferença e desigualdade: Construindo a escola possível}

Os novos desafios a serem enfrentados pelo Ensino Médio, portanto, precisam ser compreendidos com base na identificação das verdadeiras causas, para propor medidas que não sejam ideológicas, populistas, demagógicas ou clientelistas (Mato Grosso 1997).

Do ponto de vista da nova concepção, tem-se clareza de que ela só será plenamente possível numa sociedade em que todos desfrutem igual- 
mente das mesmas condições de acesso aos bens materiais e culturais socialmente produzidos. Ou seja, numa sociedade em que os jovens possam exercer o direito à diferença sem que isso se constitua em desigualdade, de tal modo que a escolha por uma trajetória educacional e profissional não seja socialmente determinada pela origem de classe. Ou, exemplificando, que a decisão de não cursar o nível superior corresponda ao desejo de desempenhar uma função que exija qualificação mais rápi$\mathrm{da}$, mas que seja igualmente valorizada socialmente, propiciando trabaIho e vida digna; isso exigiria que potencialmente existissem vagas para todos que desejassem ingressar no Ensino Superior.

Tal não acontece, e o Brasil, particularmente, está muito distante dessa possibilidade; as vagas em número insignificante configuram uma situação em que o acesso a esse nível - em particular aos cursos nobres, que exigem tempo integral, escolaridade anterior de excelência, financiamento de material técnico, bibliográfico, além de cursos complementares à formação - é reservado àqueles de renda mais alta, ressalvadas algumas exceções que continuam servindo à confirmação da tese da meritocracia. Ao mesmo tempo, o mundo do trabalho reestruturado, no âmbito da globalização da economia, restringe cada vez mais o número de postos, enquanto cria, ou recria, na informalidade, um sem-número de ocupações precárias que, embora ainda sirvam à sobrevivência, longe estão de permitir um mínimo de dignidade e cidadania.

É com essa realidade que o Ensino Médio deverá trabalhar, ao estabelecer suas diretrizes curriculares: um imenso contingente de jovens que se diferenciam por condições de existência e perspectivas de futuro desiguais. É com base nela que se há de tratar a concepção.

Se, por um lado, a crítica à dualidade estrutural mostra seu caráter perverso, por outro, simplesmente estabelecer um "modelo dito único", tal como o proposto na Resolução 03/98 CNE, não resolve a questão, posto que submeter os desiguais a igual tratamento só faz aumentar a desigualdade.

É exatamente com essa compreensão que a LDB, ao apontar o caráter básico do Ensino Médio, e a necessidade de assegurá-lo para todos, permite distintas modalidades de organização, inclusive a habilitação profissional, com o intuito de tratar diferentemente os desiguais, conforme seus interesses e suas necessidades, para que possam ser iguais.

Pensar, pois, em oferecer um Ensino Médio de uma única modalidade, em substituição aos distintos ramos de ensino técnico que vinham sendo oferecidos para atender às demandas do taylorismo/fordismo, é 
tão inadequado quanto manter a estrutura que existia até agora, com um ramo de educação geral e outro de educação profissional.

Nesse quadro, há que buscar o avanço possível, considerando os recursos disponíveis, na escola concreta, com suas possibilidades e limitações, na contramaré da exclusão. Será necessário, portanto, formular diretrizes que priorizem uma formação científico-tecnológica e sóciohistórica para todos, no sentido da construção de uma igualdade que não está dada no ponto de partida, e que, por essa mesma razão, exige mediações diferenciadas no próprio Ensino Médio, para atender às demandas de uma clientela diferenciada e desigual.

Não há que se fazer concessão ao caráter básico do Ensino Médio, supondo ser possível sua substituição pela educação profissional independentemente da escolaridade. Contudo, já no Ensino Médio, a formação científico-tecnológica e sócio-histórica deverá ser complementada, na parte diversificada, por conteúdos do mundo do trabalho, sem que se configurem os cursos profissionalizantes típicos do taylorismo/fordismo.

Certamente, o tratamento teórico-metodológico adequado dos conteúdos das áreas de códigos e linguagens, ciências da natureza, matemática e ciências humanas, todas complementadas com o estudo das formas tecnológicas, se efetivamente viabilizado, fornecerá o necessário suporte à participação na vida social e produtiva.

Contudo, esse tratamento não será suficiente para certas clientelas, para as quais o Ensino Médio é mediação necessária para o mundo do trabalho, e nesses casos condição de sobrevivência. Para atender às necessidades dessa clientela, alguma forma de preparação para a realização de alguma atividade produtiva deverá ser oferecida. Não fazêlo significará estimular os jovens que precisem trabalhar ao abandono do Ensino Médio, ou mesmo à sua substituição por cursos profissionais, abrindo mão do direito à escolaridade e à continuidade dos estudos.

Lembrando Gramsci (1978, p. 136), é sempre bom ter claro que as escolas são antidemocráticas não pelos conteúdos que ensinam - acadêmicos, "desinteressados", ou técnico-profissionalizantes, "interessados" -, mas por sua função, a de preparar diferentemente os intelectuais segundo o lugar que irão ocupar na sociedade, e portanto segundo sua origem de classe, como dirigentes ou como trabalhadores.

Para a maioria dos jovens, o exercício de um trabalho digno será a única possibilidade de continuar seus estudos em nível superior. O Ensino Médio deverá responder ao desafio de atender a estas 
duas demandas: o acesso ao trabalho e a continuidade de estudos, com competência e compromisso.

Ao assumir que os compromissos do Ensino Médio referem-se a todos os adolescentes, independentemente de sua origem de classe, é preciso destacar o papel da escola pública na construção de uma proposta pedagógica que propicie situações de aprendizagem variadas e significativas a seus estudantes, de modo geral pauperizados economicamente, e, em conseqüência, cultural e socialmente.

Embora esta afirmação pareça óbvia, é sempre bom lembrar que o Ensino Médio no Brasil tem exercido, entre outras, a função de referendar a inclusão dos incluídos, justificada pelos resultados escolares. Na verdade, os incluídos vivenciam um conjunto de experiências sociais e culturais que lhes assegura larga vantagem na relação com o conhecimento sistematizado, isto sem falar nas condições materiais favoráveis ao estabelecimento dessa relação. Assim é que, não por coincidência, os que permanecem na escola são também os que melhor se comunicam, têm melhor aparência, dominam mais conhecimentos e apresentam condutas mais adequadas ao disciplinamento exigido pela vida escolar, produtiva e social.

A escola pública de Ensino Médio só será efetivamente democrática quando seu projeto pedagógico, sem pretender ingenuamente ser compensatório, propiciar as necessárias mediações para que os filhos de trabalhadores e excluídos estejam em condições de identificar, compreender e buscar suprir, ao longo de sua vida, suas necessidades em relação à produção científica, tecnológica e cultural.

É essa nova compreensão que permitirá superar a profissionalização estreita, restrita à apropriação de modos de fazer, voltada para uma parcela da população condenada a priori à pobreza cultural, tida como irremediável em virtude da pobreza econômica, para a qual, em princípio, qualquer esforço pedagógico será inútil. Ao contrário, a escola média compreenderá que os culturalmente diferentes, porquanto desiguais em relação à propriedade, desde cedo se relacionam com o trabalho, com base no que elaboram sua própria cultura e produzem saber, no transcurso das relações sociais e produtivas das quais participam; e que essas experiências circunscritas à origem de classe resultarão em limitações em relação à apropriação da ciência oficial e da cultura dominante.

Em decorrência, a escola média deverá ser capaz de, articulando ciência, trabalho e cultura, exercer a sua função universalizadora, por meio de um projeto político-pedagógico que permita o enfrentamento de tais limitações. 
Do mesmo modo, essa nova compreensão entenderá que a manutenção da proposta secundarista e acadêmica só serve aos já incluídos, cuja relação com o conhecimento e com a cultura se dá, de forma rica e diversificada, fora da escola. Daí o caráter propedêutico ser adequado a essa clientela, cuja relação com o trabalho produtivo dar-se-á no Ensino Superior como formação, e, após sua conclusão, como exercício laboral, nas funções técnico-científicas e de gestão mais intelectualizadas e complexas, embora atualmente mais restritas pelo mercado, que exige cada vez mais numerosas e diversificadas competências.

Elaborar a nova síntese entre o geral e o particular, entre o lógico e o histórico, entre a teoria e a prática, entre o conhecimento e o trabaIho, entre estes e a cultura é a nova finalidade do Ensino Médio: ser geral sem ser genérico, incorporando o trabalho sem ser profissionalizante, no sentido estreito.

O Ensino Médio, assim concebido, poderá ter o seu projeto pedagógico contemplando diferentes conteúdos em diferentes modalidades, para atender às especificidades de seus jovens clientes, diferentes e desiguais social e economicamente. Ele será unificado pela sua finalidade, que expressa o compromisso com a igualdade de direitos, não como um atributo formal assegurado pela legislação, mas como uma conquista real, processo histórico de destruição das desigualdades, que se dá pela atividade real dos homens, da qual a escola participa.

Até agora, o processo histórico, em face da organização taylorista/ fordista, criou espaço para a proliferação de escolas profissionais para atender às necessidades das várias áreas de atuação, que foram se diversificando de forma caótica e desordenada. Esse tipo de escola, preocupada em satisfazer os interesses práticos imediatos do mercado, foi louvada como democrática, quando, na realidade, não só foi destinada a perpetuar as diferenças sociais como ainda a cristalizá-las (Gramsci 1978, p. 136).

A nova escola média, portanto, poderá trabalhar com conteúdos diferentes para alunos cujas relações com o trabalho, com a ciência e com a cultura ocorrem diferentemente, desde que sua finalidade, articulada à de um projeto político e econômico mais amplo, seja fazer emergir, em todos os alunos, no dizer de Gramsci, o verdadeiro dirigente, porquanto nem só especialista e nem só político, mas expressão de um novo equilíbrio entre o desenvolvimento das capacidades de atuar praticamente e de trabalhar intelectualmente, tendo em vista a construção de relações justas e igualitárias.

O desenvolvimento histórico do Ensino Médio no Brasil caracterizou-se pela heterogeneidade em todos os aspectos, da finalidade à 
estrutura física. Essa heterogeneidade, somada às diferenças e desigualdades do alunado e às especificidades regionais, determina a necessidade da oferta de programas diversificados, estimulando a criação de alternativas, desde que se observe a base comum, as diretrizes curriculares nacionais e as normas complementares estaduais.

Dessa forma, cabe a cada escola a elaboração de um projeto político-pedagógico, com base num amplo e aprofundado processo de diagnóstico, análise e proposição de alternativas, cuja elaboração demanda a participação efetiva de todos os envolvidos: comunidade, pais, alunos e professores. Esse processo deverá contemplar as características da região, as demandas da comunidade em que a escola está inserida, as características e necessidades do alunado, a capacidade da escola no que diz respeito a recursos humanos, equipamentos, espaço físico e possibilidades de articulações interinstitucionais que permitam ofertas diversificadas e de melhor qualidade.

Em face da crise de financiamento, é preciso decidir com realismo e buscar a otimização dos recursos disponíveis na escola e na comunidade, o que não significa desobrigar o Estado de suas responsabilidades, mas ter a clareza de que, para os que vivem do trabalho, a escola pública de qualidade é a única alternativa para a apropriação do conhecimento, tendo em vista a cada vez mais difícil construção da dignidade humana, finalidade máxima a orientar a elaboração do projeto político-pedagógico.

É importante destacar que a diversificação de modalidades não significa apenas reconhecer que existem preferências dos alunos segundo as diferenças individuais que levam alguns a gostar de artes, outros de comunicação, de humanidades, ciências exatas ou tecnologias, mas compreender que muitas vezes as "preferências" expressam desconhecimento ou mesmo antecipada consciência de impossibilidade, em decorrência de experiências anteriores determinadas pelas condições materiais de existência. Assim é que um aluno pode preferir mecânica a arte, porque essa é a realidade do trabalho que conhece e exerce precocemente como estratégia de sobrevivência; outro pode preferir atividades físicas a ciências exatas porque suas experiências de classe não lhe propiciaram o desenvolvimento do raciocínio lógico.

É a escola, portanto, que Ihe propiciará oportunidades de estabelecer relações com os distintos campos do conhecimento, no sentido de exercer seu direito a escolhas, ao mesmo tempo que supera suas dificuldades em face de suas experiências anteriores. Isso significa afirmar que a diversificação de modalidades deverá preparar o aluno para exercer 
atividades produtivas na área de mecânica, usando conhecimentos científicos e tecnológicos para resolver os problemas que a prática lhe coloca, até porque disso depende sua sobrevivência, e não precisará ser profissionalizante para fazê-lo; mas deverá também colocá-lo em contato com a arte por meio de experiências significativas, de modo que ele possa perceber o senso estético como uma forma peculiar da práxis humana, presente em todos os espaços da vida social e produtiva. Aos que não desenvolveram as capacidades de comunicação e de raciocínio lógico em virtude de sua história de vida e de sua escolaridade, a escola deverá propor espaços de aprendizagem especialmente planejados para esse fim.

Ou seja, a escola média deverá assumir que a unitariedade, ao contrário do discurso oficial, é o ponto de chegada em outras condições históricas, em que as diferenças não mais sejam fruto das desigualdades em relação à propriedade privada dos meios de produção. Tomando, pois, as desigualdades no ponto de partida, deverá desenvolver projetos político-pedagógicos que, com diferentes e necessárias mediações, tratem de forma diferente os desiguais, como parte da estratégia mais ampla de destruição das bases materiais que determinam as desigualdades.

O discurso oficial, quando aponta a suposta unitariedade de uma escola secundarista cujo conteúdo é de classe, ao tratar a todos igualmente, responde às novas demandas do mercado globalizado, reestruturado e excludente, na medida em que exclui, e justifica a exclusão, pelo demérito individual, uma vez que são dadas "oportunidades iguais " a todos.

\section{Otrabalho não é vida?}

As afirmações "educação agora é para a vida" e "educação profissional é um complemento à educação básica" são feitas com base na constatação da identidade entre as capacidades demandadas pelo exer-

cício da cidadania e pela atividade produtiva. Essa identidade permitiria superar a dicotomia entre os ideais de formação humana, que perderiam seu caráter abstrato, e as demandas da produção, que por sua vez se humanizariam (Tedesco 1998, p. 51).

Com a progressiva perda de conteúdo do trabalho, que vai se tornando cada vez mais abstrato pela crescente incorporação de ciência e tecnologia ao processo produtivo para atender aos objetivos da acumulação, a formação intelectual, demanda até então restrita a um número reduzido de funções, passa a ser requerida para o conjunto dos postos 
transformados pela reestruturação produtiva. Embora esse processo não atinja da mesma forma o conjunto das atividades produtivas, não podendo a nova demanda ser generalizada, aos novos paradigmas corresponde uma nova cultura, marcada pela presença de novas tecnologias que permanentemente se transformam, e, ao fazê-lo, também transformam todas as dimensões da vida social e produtiva, ainda que com impactos diferenciados, particularmente num país como o Brasil, onde as desigualdades são muito acentuadas (Harvey 1992).

Gorz refere-se a esse fenômeno como banalização das competências, não no sentido da desqualificação e da rotinização do trabalho, mas como ampliação do acesso às competências que a atividade nos postos que não se precarizaram exige. Não há mais monopólio de competências, e todos podem aprender a fazer muitas coisas.

Ao mesmo tempo, as mudanças ocorridas no mundo do trabalho passam a exigir realmente uma nova relação com o conhecimento para que se possa viver em sociedade, o que, para a grande maioria da população, só pode ocorrer por intermédio da escola.

Para entender essa afirmação é preciso ter claro que os impactos das mudanças ocorridas no mundo do trabalho sobre a educação dos trabalhadores não se dão de forma linear. Se assim fosse, a tendência seria de diminuição das demandas de educação, em razão não só do caráter poupador de mão-de-obra, mas também da mudança da natureza do trabalho, cada vez mais abstrato, isto é, cada vez mais simplificado e, portanto, com menos exigência de capacitação específica. No entanto, as mudanças ocorridas nas bases materiais provocam verdadeira revolução nas relações sociais, estabelecendo uma nova cultura, cada vez mais perpassada por ciência e tecnologia, que por sua vez demanda também maiores aportes de conhecimento sócio-histórico para fazer frente às contradições decorrentes do desenvolvimento capitalista.

Evidencia-se, portanto, a necessidade de apropriação, pelos que vivem do trabalho, de conhecimentos científicos, tecnológicos e sócio-históricos, com particular destaque para as formas de comunicação e de organização e gestão dos processos sociais e produtivos, para além das demandas da acumulação capitalista.

Ou seja, por contradição, a necessidade do estabelecimento de outra relação com o conhecimento, na perspectiva do já produzido e dos caminhos metodológicos para a sua produção, tendo em vista o enfrentamento da exclusão, generaliza-se para os que historicamente têm vivido do trabalho. 
Resulta daí o reconhecimento do caráter conservador tanto das análises que afirmam as demandas do capital relativas à generalização e à ampliação da educação dos trabalhadores na estrita perspectiva da formação profissional, por não encontrarem respaldo nas práticas produtivas, quanto daquelas que negam essas mesmas necessidades para os trabalhadores, com base na consideração estreita das ofertas do mercado de trabalho, tal como faz o discurso oficial.

A necessidade de formação na escola, portanto, é colocada para aqueles que, por viver do trabalho, são pauperizados economicamente, e, em decorrência, também o são culturalmente. Para estes, a escola é o único espaço disponível para apreender e compreender o mundo do trabalho, pela mediação do conhecimento, como produto e como processo da práxis humana, na perspectiva da produção material e social da existência.

O que é necessário destacar é que, ao momento que tais mudanças ocorrem, estabelecendo-se algumas condições materiais para o desenvolvimento de um projeto político-pedagógico que identifique educação para a cidadania e para o trabalho, há uma outra condição material que passa a ter caráter dominante: extinguem-se os postos formais e muda a forma de trabaIho, deixando de ser dominante a relação de assalariamento. A precarização do trabalho, forma que tende a ser dominante, por sua vez, inviabiliza o acesso à educação e aos demais direitos mínimos de cidadania, desaparecendo as condições para a "banalização das competências", no sentido da sua desmonopolização, que continua a ser prerrogativa de uma classe social.

Assim, o discurso ideológico do governo torna-se necessário para apresentar uma concepção de classe - a identidade entre educação para a vida e educação para o trabalho - como universal.

Nesse contexto de mudanças, a nova relação entre educação e trabalho, agora mediada pelo conhecimento, passa a ser absorvida diferentemente pelos Estados nacionais, em face de sua posição no capitalismo globalizado. De modo geral, essa posição será definida com base no novo papel do Estado em relação à oferta de educação, que se configura diferentemente daquela assumida sob a hegemonia do taylorismo/fordismo. Nesse modelo de organização da sociedade e da produção, a formação profissional de grandes contingentes de trabalhadores, particularmente dos pouco qualificados, era estratégica para o capital, assumindo o Estado o compromisso com a sua oferta, em situação próxima à de pleno emprego. As demandas, contudo, não passavam da educação primária, completada por alguma formação profissional, a ser adquirida em situações variadas, geralmente na esfera privada. Nesse contexto, era orgânica a 
concepção de universalização do que se considerava educação básica, e o Estado brasileiro a assumiu, incluindo-a no texto constitucional.

Com a acumulação flexível, o capital prescinde de formação profissional para os postos crescentemente simplificados, passando a demandar do Estado apenas educação geral, mais ampliada, é verdade, porém não mais universalizada, em face da redução dos postos de trabalho. Para a educação de seus profissionais qualificados, o capital sempre prescindiu do Estado, provendo suas próprias demandas, em face do caráter estratégico. Nesse novo contexto, tomando por princípio a racionalidade econômica, de fato não há por que estender a educação média tecnológica aos sobrantes. A educação fundamental será suficiente, uma vez que, para a maioria, o horizonte é o exercício de tarefas precarizadas de caráter eventual, com reduzidas oportunidades de participação na cultura, na política e na sociedade. Nessa perspectiva, a universalização do Ensino Fundamental, limite auto-imposto pelo governo, vincula-se antes à finalidade de exercer algum controle social, para evitar a completa barbarização, do que ao atendimento dos direitos de cidadania.

O resultado disso tudo é a perpetuação e o aprofundamento da dualidade, justificada pela ideologia presente nas reformas, que nada mais faz do que tentar esconder que a educação proposta como universal é para muito poucos, restando para a grande maioria uma versão piorada da pedagogia taylorista/fordista, da qual os cursos aligeirados de "desqualificação profissional básica" propostos pelo Decreto 2208/97 são o melhor exemplo.

Para finalizar os contornos do processo de disseminação ideológica em curso, o Estado, por meio da reforma administrativa, substituiu a concepção de público estatal pela concepção de público não-estatal, deixando para o setor privado, ou seja, para o mercado, a regulação dos direitos mínimos de cidadania, o que obedece à lógica de só assegurar o que é estratégico para a acumulação flexível, tanto na esfera pública quanto na privada. E, evidentemente, a universalização da educação média tecnológica não se enquadra nesse perfil. Portanto, para os "bem incluídos", compre-se no mercado. Para os demais, a velha escola risonha e franca, com todas as sua antigas mazelas, agora pomposamente chamada de única e "para a vida"... sofrida, precarizada, "não vida" na ausência dos direitos!

Do ponto de vista teórico, a concepção oficial até se justificaria ao tomar o trabalho na sua concepção de práxis humana, ou seja, como o conjunto de ações materiais e espirituais que o homem, como indivíduo e humanidade, desenvolve para transformar a natureza, os outros homens e a si mesmo, com a finalidade de produzir as condições necessárias à sua 
existência, dominante nas formas pré-capitalistas. (Marx e Engels, s./d.). Essa é a concepção presente nas Diretrizes Curriculares para o Ensino Médio, com base na qual a proposta de educação tecnológica é apresentada como a síntese que permitiria superar a dicotomia entre formação para a cidadania e para o trabalho. Desse ponto de vista, toda e qualquer educação sempre será educação para o trabalho.

A ninguém ocorreria afirmar que o conhecimento da língua portuguesa, ou mesmo da estrangeira, não seja educação para o trabalho. O mesmo pode ser dito em relação à química, à biologia ou à matemática, particularmente no mundo contemporâneo, onde qualquer forma de ação, seja ela produtiva ou não, exige o domínio de múltiplos conhecimentos articulados entre si. Nesse sentido, pode-se afirmar categoricamente que a novidade em termos de finalidade, não só para o Ensino Médio, mas para todos os níveis de ensino, é o desenvolvimento da capacidade de usar conhecimentos científicos de todas as áreas para resolver as situações que a prática social e produtiva apresenta ao homem cotidianamente. Isso porque, nesse estágio de desenvolvimento da sociedade capitalista, apenas o conhecimento prático e o bom senso, embora continuem a ser importantes, não são mais suficientes para enfrentar os desafios postos por um modelo de desenvolvimento que cada vez mais usa a ciência como força produtiva, para o bem e para o mal, ao mesmo tempo melhorando e destruindo a qualidade de vida, individual e social.

Baseando-se nessa concepção é possível afirmar que as finalidades e os objetivos do Ensino Médio se resumem no compromisso de educar o jovem para participar política e produtivamente do mundo das relações sociais concretas, pelo desenvolvimento da autonomia intelectual e da autonomia ético-política.

Embora avançada e teoricamente correta, essa concepção que entende o trabalho como práxis humana para definir a identidade do Ensino Médio, se tomada em si, apresenta problemas, que se evidenciam quando são analisadas as condições concretas do aluno brasileiro que aspira a esse nível de ensino.

Isso porque essa concepção não toma o trabalho tal como ele se manifesta histórica e concretamente no capitalismo: como diretamente produtivo, gerador de renda e, portanto, absolutamente necessário para assegurar condições dignas de vida e de cidadania. Trabalho que, compreendido nessa dimensão, cada vez mais se apresenta como espaço para poucos, em face das características do modelo de desenvolvimento em curso, estruturalmente excludente. 
Essa afirmação pode ser analisada de dois pontos de vista. Se tomada do ponto vista do capital, tem lógica a transferência da formação profissional para os níveis pós-médio e superior, uma vez que, sob a justificativa da meritocracia, a seletividade do sistema escolar desempenha seu papel excludente, preparando apenas os melhores para os postos de trabalho disponíveis no mercado, cada vez em menor número. Do ponto de vista dos trabalhadores, essa transferência assume feições perversas, visto que, para os que vivem do trabalho, a aprendizagem de conhecimentos e habilidades, manuais e cognitivas vinculadas ao exercício de atividades produtivas, é condição não só de existência, mas também da própria permanência no sistema de ensino, na maioria das vezes possível apenas pela via privada.

Outro risco a apontar, quando se toma o conceito de trabalho em geral ao propor o novo modelo de Ensino Médio, reside no fato de que aquilo que está em tudo corre o risco de não estar em lugar nenhum. Ou seja, ao considerar que todos os conteúdos são formação para o trabalho, justificase um currículo academicista e livresco, genérico sem ser geral, de baixo custo e sem exigência de rigor e competência no trabalho docente, que, longe de atender às novas demandas do mundo contemporâneo, apenas reproduza a velha versão secundarista, de caráter propedêutico, que já não atende sequer à burguesia, a não ser quanto à certificação, posto que os conhecimentos a ela necessários serão buscados em outros espaços.

$\mathrm{E}$, finalmente, há que retomar a constatação já feita anteriormente, acerca da polarização das competências, para indicar, como faz Tedesco, o paradoxo deste final de século: quando finalmente as exigências de competitividade econômica reclamam o uso intensivo do conhecimento e da educação, estreitando as relações entre educação e trabalho, desaparece a especificidade do vínculo formal com o emprego, transferindo-se a tensão para outro ponto: embora educação para a cidadania e para o trabalho se confundam, ela é para poucos; cada vez para menos.

Assim, há que tomar o discurso oficial à luz das condições que estão historicamente dadas, particularmente no que diz respeito ao modelo de desenvolvimento em curso, que acentua, nos países periféricos, as contradições entre capital e trabalho, corroendo os fundos públicos, extinguindo postos de trabalho e aumentando a exclusão. Desse ponto de vista, fica evidente que a adoção do conceito de trabalho exclusivamente como práxis humana, elidindo seu caráter de prática produtiva, esconde a intenção de assegurar a continuidade dos incluídos, sob a alegação do mérito acadêmico, ocultando as verdadeiras causas da exclusão dos que vivem do trabalho em uma escola que privilegia um mo- 
delo que atende às características dos que estabelecem relações significativas com o conhecimento socialmente necessário fora da escola, em razão de sua origem de classe.

$E$, dessa forma, justifica a educação dos jovens na justa medida das demandas do mercado de trabalho: para uns poucos, a qualificação científico-tecnológica e sócio-histórica para o exercício das funções vinculadas à gestão, à criação, à direção e aos serviços especializados; para a grande maioria, a escolaridade apenas suficiente para permitir o domínio dos instrumentos necessários à existência em uma sociedade de perfil científicotecnológico, complementada por formação profissional de curta duração, que os capacite para exercer ocupações precarizadas em um mercado cada vez mais restrito, e, principalmente, evite a barbárie, permitindo a continuidade da acumulação capitalista.

Em resumo, a efetiva democratização de um Ensino Médio que ao mesmo tempo prepare para a inserção no mundo do trabalho e para a cidadania, complementado nos níveis subseqüentes por formação profissional científico-tecnológica e sócio-histórica, tal como o proposto nas finalidades expressas na legislação, exige condições materiais que não estão dadas no caso brasileiro.

Em decorrência, além de demonstrar o caráter ideológico da reforma, é preciso retomar o trabalho em sua dupla dimensão, como práxis humana e como práxis produtiva, estabelecendo o Ensino Médio relações mais imediatas com o mundo do trabalho sempre que os jovens, pela sua origem de classe, precisem desenvolver competências laborais para assegurar sua sobrevivência e a sua permanência na escola.

Isso significa que a aproximação das finalidades do Ensino Médio farse-á por diferentes mediações, em face das condições concretas de cada região, de cada localidade, de cada escola, de cada clientela.

Mais do que nunca, o Ensino Médio deverá superar a concepção dual e conteudista que o tem caracterizado, em face de sua versão predominantemente propedêutica, para promover mediações significativas entre os jovens e o conhecimento científico, articulando saberes tácitos, experiências e atitudes. Essa mudança é imperativo de sobrevivência num mundo imerso em profunda crise econômica, política e ideológica, em que a falta de alternativas de existência com um mínimo de dignidade, articulada à falta de utopia, tem levado os jovens ao individualismo, ao hedonismo e à violência, em virtude da perda de significado da vida individual e coletiva.

Para não ceder ao fatalismo, há uma pequena possibilidade, limitada também por todas as condições de precarização das escolas públi- 
cas e de seus professores: o projeto político-pedagógico define-se, teórica e praticamente, nas escolas. Talvez por aí se construam algumas alternativas possíveis, nas condições historicamente dadas!

Recebido para publicação em março de 2000

\section{High school now is for life: Among what's intended, what's said and what's done.}

ABSTRACT: This paper intends to uncover the ideology of official speech affirming that the new High School now is for life, substituting the old model where the general education was integrated with a professional learning in the same net, is understood as "not life". The author will show that, besides the official speech, the new proposal serves just to the social elite. The author has a different proposal that gives access to everyone in all knowledge areas showing the actual possibility of the high school as an instrument of social equality.

\section{Referências bibliográficas}

BANCO MUNDIAL. La ensenãnza superior: Las lecciones derivadas de la experiencia. Washington, 1995.

CONSELHO NACIONAL DE EDUCAÇÃO. Resolução $n^{\circ} 3$, de 5 de março de 1998. Documenta. Brasília, $n^{\circ} 438$, p. 89, mar. 1998. Publicada no D.O.U. de 9/3/1998, Seção I, p. 87.

DEJOURS, Chistophe. A banalização da injustiça social. Rio de Janeiro: Ed. Fundação Getúlio Vargas, 1999.

GOVERNO DO ESTADO DO MATO GROSSO. Novas perspectivas para o Ensino Médio. Cuiabá: Secretaria de Estado da Educação, 1997.

GRAMSCI, Antonio. Os intelectuais e a organização da cultura. Rio de Janeiro: Civilização Brasileira, 1978.

HARVEY, D. A condição pós-moderna. São Paulo: Loyola, 1992.

KUENZER, Acacia Z. Ensino Médio e profissional: As políticas do Estado neoliberal. São Paulo: Cortez, 1997.

MARX, K. e ENGELS, F. A ideologia alemã. Portugal: Martins Fontes, s./d.

TEDESCO, Juan. O novo pacto educativo. São Paulo: Ática, 1998. 